\title{
SURFACE TEMPERATURE ANALYSIS OF THE BOARD WITH BUILT-IN INFRARED HEATING
}

\author{
${ }^{1}$ Dominik DUBECKÝ, ${ }^{2}$ Mária KOZLOVSKÁ \\ ${ }^{1,2}$ Department of Construction Technology and Management, Faculty of Civil Engineering \\ Technical University of Kosice, Vysokoskolska 4, 04200 Kosice, Slovakia \\ e-mail: ${ }^{1}$ dominik.dubecky@tuke.sk, ${ }^{2}$ maria.kozlovska@tuke.sk
}

Received 29 December 2017; accepted 12 March 2018

\begin{abstract}
The paper presents partial results of research and develops of innovative board with built-in infrared heating film. The base of technical solution of innovative board is enclosed by the infrared heating film between two construction boards. The paper presents partial outputs related to the research of the innovative board efficiency in relation to surface temperature. The methodology for measuring the surface temperature of the board was determined as a part of the board initial research. Surface temperature sensors were used for measurement. Time required to achieve the reference surface temperature of the board was investigated after switching on the heating film. The results of partial measurements offer the basis for further analysis and research of the innovative board.
\end{abstract}

Keywords: Innovative board, Surface temperature, Infrared heating, Construction

\section{Introduction}

The construction sector is characterized by high proportion of manual work from construction processes point of view. For example, the family house construction consists of approximately 290 activities. The processes are interconnected and mutually contingent. The human factor greatly affects the efficiency of construction work, therefore it is necessary to develop and use construction products, which eliminated manual work. One of the construction processes in the residential construction is realization the heating system. The heating system can be divided from different point of view. Depending on media, which provides the warm it is heating system based the most on the water, electricity, air. Depending on realization technology heating system 
can be divided on to system built-into the 'wet' layers (typical is warm water floor heating system) or on to system built-into the 'dry' layers (electric heating or low temperature infrared heating system). Heating system can be divided also from location point of view on to system built into the floor, ceiling or wall. All of above systems need media distribution (water pipes, electric cables or air channels) build separately and all the processes have to be strictly coordinated with other construction processes. The InfraRed (IR) heating system starts to be more popular because it eliminates many of these constraints. This heating system is comfortable which is advantageous, because good environmental interior quality is necessary in the residential and commercial buildings [1], [2].

Infrared heating system does not need so many processes compared with warm water or air heating systems. It is electric heating system, where the warm comes not from electric cables but from infrared heating source. The basic principle of its functioning is based on the discovery from $11^{\text {th }}$ February 1800 when William Herschel finds out existence of infrared [3]. Infrared radiation is emitted from all surface whose temperature is more than $-273.15^{\circ} \mathrm{C}(0 \mathrm{~K})$, which is absolute zero. Primary function of infrared heater is transferring heat to the target through the emission of IR radiation [4].

Using infrared heating system in buildings has more positives not only from the construction point of view. It is achieved energy efficient heating because of the radiant heat exchange between the source and the irradiated area. The thermal response of heating system is fast and heating system needs shortly time to be warm [5]. No more important is that the source for IR heating system is electrical energy and it can be provided by green energy. Therefore this system can be long-term sustainable. Infrared heating film provides above benefits for the buildings. The heating film is basic element of heating system.

The infrared heating film consists from the carbon paste, which fills the heater function. This paste can be as a strip or fully distributed layer. Distribution of the electricity in the IR heating film is provided by the booth bar, which connected carbon paste. Base and laminex film provides the protection and connection all layers in to the one film. Using this heating system is less complicated in terms of number of activities required for its installation into the building. It is not necessary to realize pipe for water or tube for air and also it is not necessary to store the heating cable in to the construction.

In an effort to achieve more effective construction process in the field of heating system authors of the article are developing the board with built-in infrared heating film. This board is protected by valid utility model $\mathrm{Nr}$. 7722 [6] and the technical solution is that the infrared heating film is enclosed by two boards. Therefore the boards consist from three basic layers: bearing board, infrared heating film and cowering board. The main benefit for using this board is that the montage of the construction board and realization of the heating is made in one step. For finishing the heating system, all innovative heating boards are only connected between each other.

Bearing board and cowering board are standard construction board. It is possible to use different types and thickness of the boards. Therefore it is necessary to know behavior of the different boards for setting the construction of the final board. In this article is analyzed rising of surface temperature of three board types. This analysis is one of the initial researches of innovative board. 


\section{Materials and methods}

By this experiment was analyzed time for achieving the reference surface temperature on different boards after turning the IR heating film ON. For comparing were used three types of boards, which are common used in the construction:

- Oriented Strand Board (OSB) - KRONOPOL ${ }^{\circledR}$ OSB 3 KRONO P+D with dimension $500 \mathrm{~mm} \times 500 \mathrm{~mm}$ and thickness $12 \mathrm{~mm}$;

- Gypsum board - KNAUF 12.5 AK GKB with dimension $500 \mathrm{~mm}$ x $500 \mathrm{~mm}$ and thickness $12.5 \mathrm{~mm}$;

- $\mathrm{MgO}$ board - MGO Slovakia $\mathrm{MgO}$ board with dimension $500 \mathrm{~mm}$ x $500 \mathrm{~mm}$ and thickness $12 \mathrm{~mm}$.

Insulation underlay was from extruded polystyrene - POLYFORM ${ }^{\circledR}$ SYNTHOS XPS 30 IR with dimension $1250 \mathrm{~mm} \times 600 \mathrm{~mm}$, thickness $70 \mathrm{~mm}$ and $\lambda=0.035 \mathrm{~W} /(\mathrm{m} . \mathrm{K})$. Infrared heating film used for the experiment was CALEO ${ }^{\circledR}$ IR heating film with the power $130 \mathrm{~W} / \mathrm{m}^{2}$, dimension $750 \mathrm{~mm} \times 750 \mathrm{~mm}$ and thickness $0.4 \mathrm{~mm}$.

For measuring six surface temperature sensors were used AHLBORN NTC sensor FN 0001 , with operative range $-20^{\circ} \mathrm{C}$ to $+100^{\circ} \mathrm{C}$. Logging the data was provided by the logger AHLBORN ALMEMO ${ }^{\circledR} 5690-2$. The arrangement of experimental elements is shown in Fig. 1.

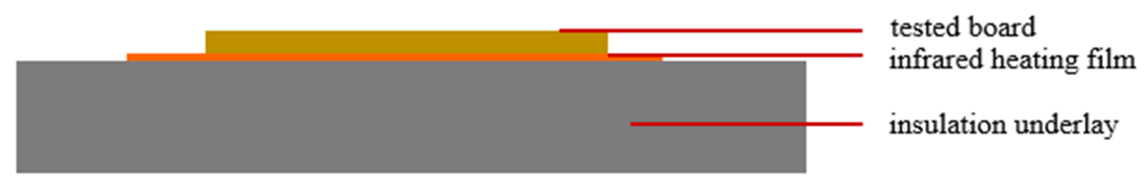

Fig. 1. The arrangement of the experiment

On the insulation underlay there was infrared heating film and on the top of IR heating film there were measured each boards. IR heating film was connected to electricity minimum 24 hour after equalizing board surface temperature with temperature in the experimental room for. Temperature in the room was $21.3^{\circ} \mathrm{C}$ $\left(+/-0.3^{\circ} \mathrm{C}\right)$. The reference surface temperature was set at $30^{\circ} \mathrm{C}$, which is the recommended surface temperature for floor heating in a residential building. This heating system provides comfortable warm for feet and then for all body [7].

The board surface was divided to three basic areas (Fig. 2) because the IR heating film has every $25 \mathrm{~cm}$ narrow area where is possible to cutting the film and where is not heated. Because of not heated area it was expected, that the surface temperature can be different in different locations. Surface temperature sensors were placed according to the scheme it is shown in Fig. 2. 


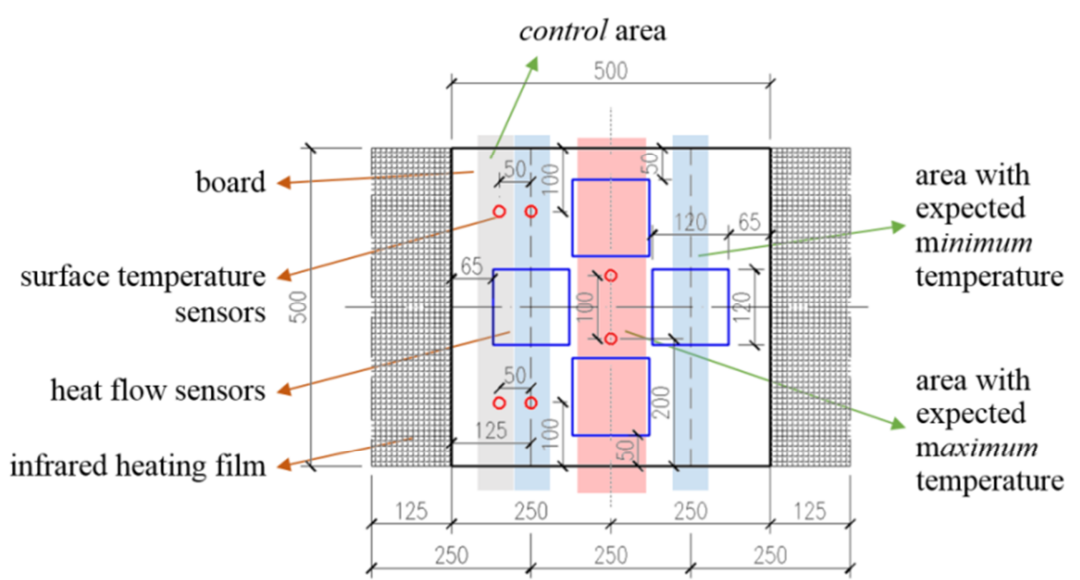

Fig. 2. Scheme of temperature sensors placing and heated areas (in $\mathrm{mm}$ )

In the area with expected maximum temperature (max) there were two sensors placed in the middle of this area and $50 \mathrm{~mm}$ out of the center. In the area with expected minimum temperature $(\mathrm{min})$ there were two sensors placed in the middle of this area and $100 \mathrm{~mm}$ out of the edge of the board. There were placed another two sensors in the control area (con). They were used to check if the lower temperature in area with expected minimum temperature is because of the non-heated area or if it is because of the placing closer to the edge of the board. Surface temperature sensors were fixed to the board surface by a tape. Experimental sample with placed sensors is shown in Fig. 3.

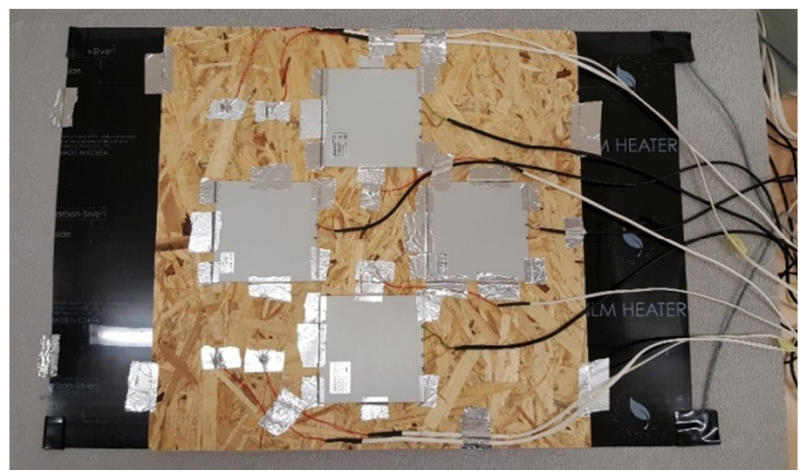

Fig. 3. Experimental sample of board with placed sensors

\section{Results and discussion}

IR heating film was turned ON when it was laying on the insulated underlay and without the board on the top. After turning ON, the film achieve reference temperature 
$30^{\circ} \mathrm{C}$ in 1.3 minutes. After 5.0 minutes there was $40^{\circ} \mathrm{C}$ on the top of the IR film and maximum surface temperature on the top was $44.2^{\circ} \mathrm{C}$ and it was achieved after 12.5 minutes.

For this experiment it was important to know behavior on the top surface of different boards after turning the film ON. In Fig. 4 - Fig. 6 increasing the temperature after turning the film ON is shown. There is shown increasing of the minimum, maximum and control temperature and there is also reference (ref) temperature.

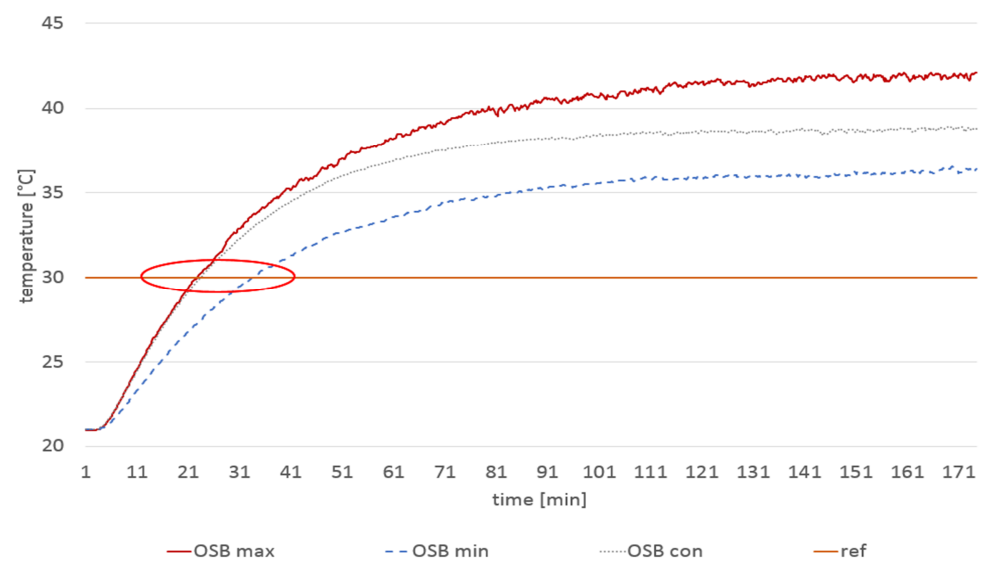

Fig. 4. Growth the temperature on the OSB board after turning the IR film ON

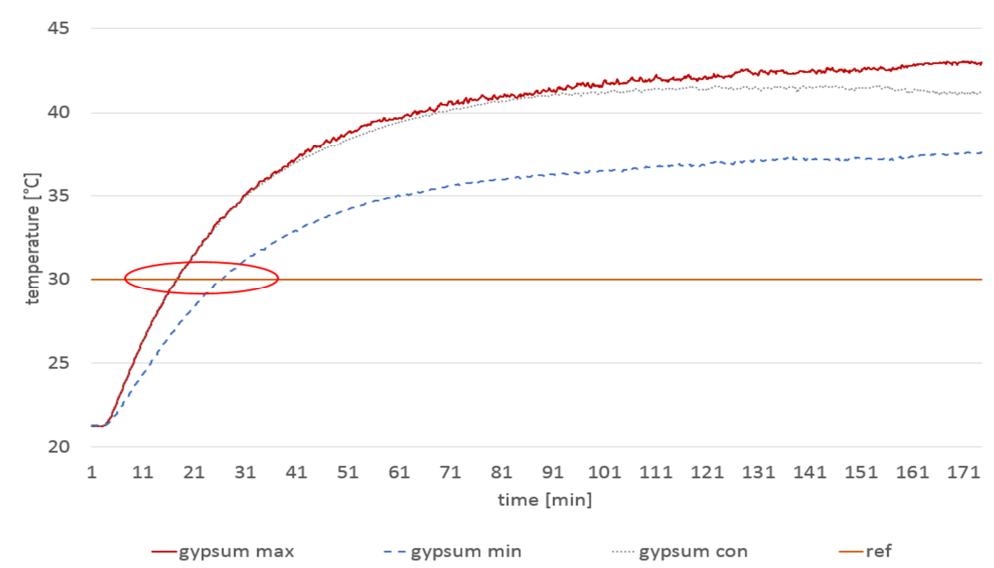

Fig. 5. Growth the temperature on the gypsum board after turning the IR film ON

Maximum temperature is shown by full red line. It is average temperature from two sensors from area with expected maximum temperature. Minimum temperature is shown by dashed blue line and it is average temperature from two sensors from area 
with expected minimum temperature. Control temperature is shown by dotted grey color and it is average temperature from two sensors from control area.

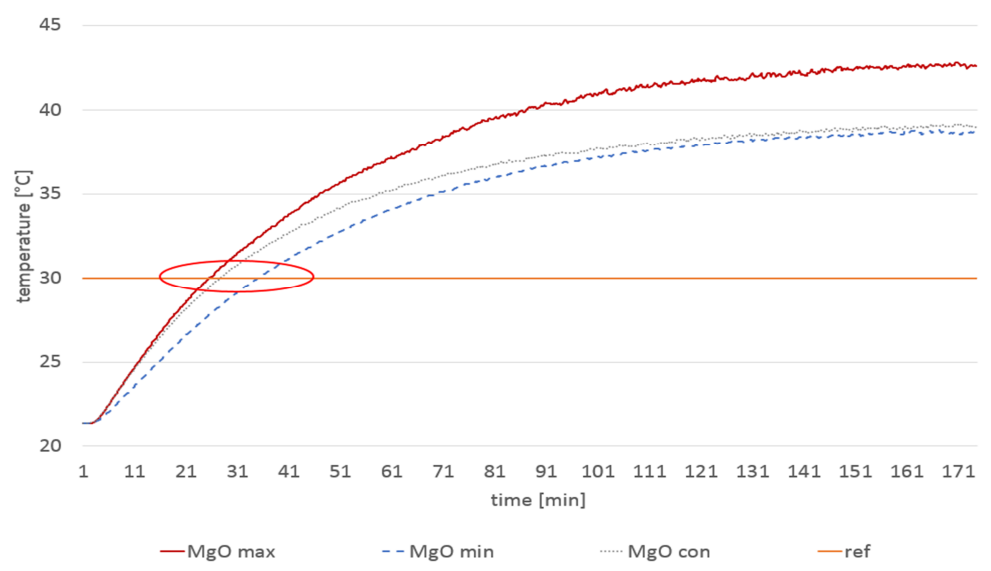

Fig. 6. Growth the temperature on the $\mathrm{MgO}$ board after turning the IR film ON

For better comparison there was determined average temperature (1) for all board examples. The average temperature depends on size of measured area.

Average temperature $=(15 \cdot \max +7 \cdot \operatorname{con}+2 \cdot \min ) / 24$

where 'max' is the maximum surface temperature, 'con' is the control surface temperature, and 'min' is the minimum surface temperature.

Calculated average temperature from surface is shown in Fig 7.

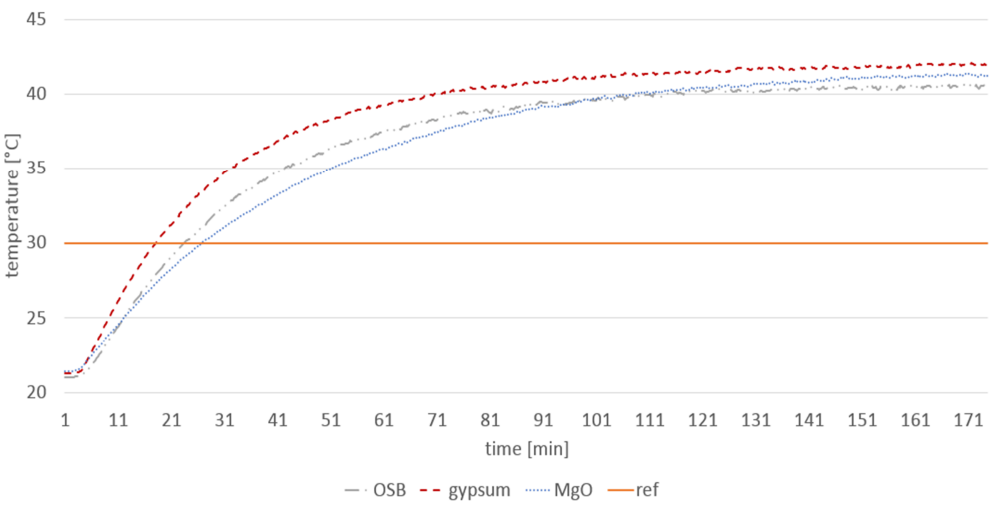

Fig. 7. Growth the average surface temperature after turning the IR film ON 
Surface temperature is shown for the OSB board by dashed-dotted line, for the gypsum board is shown by dashed line and for $\mathrm{MgO}$ board is shown by dotted line.

From measured results it is shown that the surface temperature rose differently for different materials. The boards was heated by radiation and conduction from IR heating film and therefore the time for achieving reference temperature depends on emissivity and the thermal conductivity too. Board with higher emissivity is better heated with IR energy [8]. The emissivity is the ratio of the radiation intensity of the measured element to the radiation intensity of the absolute black element with the same temperature. The emissivity of the absolute black element is 1 . The emissivity number for OSB board and gypsum board is $0.91-0.93$ [9]. The emissivity of $\mathrm{MgO}$ board is not available but it is possible to suppose that it is less than 0.9 because total emissivity for magnesium oxide is $0.2-0.55$ and for magnesite brick is 0.38 [10] and magnesium is the main component of the board. On the other hand, thermal conductivity for OSB board is $0.13 \mathrm{~W} /(\mathrm{m} . \mathrm{K})$ [11], for gypsum board it is $0.17 \mathrm{~W} /(\mathrm{m} . \mathrm{K})$ [12] and for $\mathrm{MgO}$ board is $0.216 \mathrm{~W} /(\mathrm{m} . \mathrm{K})$ [13]. The rate of growth depends on these parameters. Experiment confirms above statements and demonstrated that the gypsum board needed 17 minutes to achieve reference temperature, OSB board needed 22 minutes to achieve reference temperature and $\mathrm{MgO}$ board need up to 26 minutes.

\section{Conclusion}

The construction sector is characterized from construction processes point of view by high proportion of manual work. The construction processes are interconnected and mutually contingent. The human factor greatly affects the efficiency of construction work, therefore it is necessary to develop and use construction products, which eliminated manual work.

The paper presents partial results of research and develops of innovative board with built-in infrared heating foil. Nowadays, this board is protected by valid utility model Nr. 7722. Innovative board fulfills the construction and heating functions at the same time. The assembly of the construction board and heating system is realized in one construction process by using this innovative board. An innovative board can be built into the floor, wall and ceiling, or used as a bearing board with heating function within a Structural Insulated Panel (SIP). Using this board in buildings requires quick growth of surface temperature to achieve effective and comfortable heating. It is needed especially by building energetic efficient buildings with low temperature loss, which is nowadays necessarily.

Initial research for developing innovative board has determined the behavior of the common used construction boards. Experiment demonstrated that different boards need different time to achieve reference surface temperature. Gypsum board need the shortest time to achieving reference temperature. $\mathrm{MgO}$ board needs the longest time for achieving reference temperature. This experiment was realized by the equal thickness of boards, but it is needed to realize another experiment, because $\mathrm{MgO}$ board is available from thickness $4 \mathrm{~mm}$ compared with gypsum board which is $10 \mathrm{~mm}$ or exceptionally $6.5 \mathrm{~mm}$ thick. Finally it is possible to make a conclusion, that the efficiency of the innovative board is affected by the selected layer of construction boards. 


\section{Acknowledgements}

The article presents a partial research result of project VEGA 1/0677/14 Research of the construction efficiency improvement through the MMC technologies and follow-up project VEGA 1/0557/18 Research and development of process and product innovations of modern methods of construction in the context of the Industry 4.0 principles.

\section{References}

[1] Lipták-Váradi J. Indoor air quality measurements in Hungarian residential buildings, Pollack Periodica, Vol. 12, No. 2, 2017, pp. 163-172.

[2] Szabó J., Kajtár L. Comfort measurements in offices, Pollack Periodica, Vol. 9, No. 1, 2014, pp. 81-90.

[3] Wilson C., McGranaghan G. Infrared heating comes of age, Reinforced Plastics, Vol. 58, No 2, 2014, pp. 43-47.

[4] Butturini R., Ngo M. Flux mapping of radiant electric heaters: repeatability considerations, U.S. Consumer Product Safety Commission, 2008.

[5] Brown K. J., Farrelly R., O'Shaughnessy S. M., Robinson A. J. Energy efficiency of electrical infrared heating elements, Applied Energy, Vol. 162, 2016, pp. 581-588,

[6] Dubecký D., Kozlovská M. Prefabricated board with built-in infrared heating, valid utility model, (in Slovak) UPV SR (Industrial Property Office of the Slovak Republic), Nr. 7722, Banská Bystrica, 2016.

[7] Hesaraki A., Ploskic A., Holmberg S. Integrating low-temperature heating systems into energy efficient buildings, Energy Procedia, Vol. 78, 2015, pp. 3043-3048

[8] Chromalox Technical information, 2017, http://www.chromalox.com/catalog/resources/ technical-information/Heat-Loss-Calculations-and-Heater-Selection-Radiant-InfraredHeating.pdf, (last visited 20 December 2017).

[9] A review of interior radiation control coating research, RIMA International, 2014, https://www.solec.org/wp-content/uploads/2014/05/A-Review-of-IRCC-Research.pdf, (last visited 20 December 2017).

[10] Emissivity coefficient of some common materials, The Engineering ToolBox, 2017, https://www.engineeringtoolbox.com/emissivity-coefficients-d_447.html, (last visited 20 December 2017).

[11] Panel guide, Timber Trade Federation, 2014, http://wpif.org.uk/uploads/PanelGuide/ PanelGuide_2014_Annex2B.pdf, (last visited 20 December 2017).

[12] Thermal conductivity of common materials and gases, The Engineering ToolBox, 2017, $\mathrm{https} / / / \mathrm{www}$. engineeringtoolbox.com/thermal-conductivity-d_429.html, (last visited 20 December 2017).

[13] Dubecký D. Magnesium oxide board as a modern building material, (in Slovak) Diploma Thesis, Technical University in Košice, Košice, 2015. 